\title{
Restraint-induced hypoactivity in an elevated plus-maze
}

C.M. Padovan and F.S. Guimarães
Departamento de Farmacologia, Faculdade de Medicina de Ribeirão Preto, Universidade de São Paulo, Ribeirão Preto, SP, Brasil

\section{Correspondence \\ F.S. Guimarães \\ Departamento de Farmacologia \\ FMRP, USP \\ Av. Bandeirantes, 3900 \\ 14049-900 Ribeirão Preto, SP \\ Brasil \\ Fax: + 55-16-633-2301 \\ E-mail: fsguimar@fmrp.usp.br \\ Research supported by FAPESP (No. 98/10639-7), FINEP and CNPq. \\ C.M. Padovan and F.S. Guimarães \\ are recipients of FAPESP ( $\mathrm{N}$. . 95/ \\ 4900-6) and CN Pq fellowships, \\ respectively.}

Received December 9, 1998

Accepted November 4, 1999

\section{Abstract}

Rodents submitted to restraint stress show decreased activity in an elevated plus-maze (EPM) $24 \mathrm{~h}$ later. The objective of the present study was to determine if a certain amount of time is needed after stress for the development of these changes. We also wanted to verify if behavioral tolerance of repeated daily restraint would be detectable in this model. Male Wistar rats were restrained for $2 \mathrm{~h}$ and tested in the EPM 1, 2, 24 or $48 \mathrm{~h}$ later. Another group of animals was immobilized daily for $2 \mathrm{~h}$ for 7 days, being tested in the EPM $24 \mathrm{~h}$ after the last restraint period. Restraint induced a significant decrease in the percent of entries and time spent in the open arms, as well as a decrease in the number of enclosed arm entries. The significant effect in the number of entries and the percentage of time spent in the open arms disappeared when the data were submitted to analysis of covariance using the number of enclosed arm entries as a covariate. This suggests that the restraint-induced hypoactivity influences the measures of open arm exploration. The modifications of restraint-induced hypoactivity are evident 24 or $48 \mathrm{~h}$, but not 1 or $2 \mathrm{~h}$, after stress. In addition, rats stressed daily for seven days became tolerant to this effect.

Exposure to environmental stress has been implicated in the etiology of many human disorders such as depression, anxiety and cardiovascular disease (1).

In laboratory animals, long-lasting stressinduced effects on behavior have also been demonstrated. For example, rats submitted to $2 \mathrm{~h}$ of restraint show an exploratory deficit of new environments such as an open arena $24 \mathrm{~h}$ after the stress (2-5), suggesting that previous stressful experiences may modify the animal response to new aversive stimuli (2). Neurochemical changes such as an increase in benzodiazepine receptor affinity in the frontal cortex (6) or an increase in the 5HIAA serotonin metabolite in the same re- gion and in the hippocampus and raphe nuclei (7) have also been reported. In addition, some studies suggest that chronic restraint could induce tolerance to some of the behavioral $(8,9)$ or neurochemical $(7)$ stress-induced changes.

We have recently shown that the restraintinduced decreased activity is also evident when the animal is exposed to the elevated plus-maze, an animal model of anxiety (2-5). Using this model we have demonstrated that the restraint-induced deficit is attenuated by hippocampal injection of serotonin agonists $(2,3)$ or cycloheximide, a protein synthesis inhibitor (4).

It has been suggested that stress-induced 
Figure 1 - Elevated plus-maze exploration by rats $(\mathrm{N}=11-16) 1,2$, 24 or $48 \mathrm{~h}$ after a 2-h restraint period, as compared to nonstressed animals (Control, $\mathrm{N}=$ 65). A further group (Chronic) was tested $24 \mathrm{~h}$ after seven consecutive daily periods of 2-h restraint $(\mathrm{N}=16)$. The upper panel shows the mean ( \pm SEM) number of entries into enclosed arms. The lower panel shows the mean $( \pm$ SEM ) percentage of entries (open bars) and time spent (hatched bars) in the open arms. $* P<0.05$ compared to control (ANOVA followed by Duncan test). long-lasting behavioral changes involve plastic alterations in the central nervous system (1) which might need some time to develop. The objective of the present study was to investigate if a certain time is needed for the development of restraint-induced decreased activity in an elevated plus-maze. We also wanted to determine whether behavioral tolerance to restraint stress will also be detectable in our model.

Male Wistar rats (200-220 g) were housed in pairs in a temperature-controlled room $\left(23 \pm 1^{\circ} \mathrm{C}\right)$ under standard laboratory conditions with free access to food and water and a 12-h light cycle (lights on at 6:30 a.m.). The animals ( $\mathrm{N}=11-16 /$ group) were immobilized for $2 \mathrm{~h}$ in a wire chamber and tested in the elevated plus-maze.

The restraint chamber $(6.3 \times 19.3 \mathrm{~cm})$ was made of wire and had an adjustable roof. The wood plus-maze consisted of two open and two enclosed arms of equal length and width $(50 \times 10 \mathrm{~cm})$. The open arms had a 1$\mathrm{cm}$ high Plexiglas edge while the enclosed arms had $40-\mathrm{cm}$ high wooden sides. The

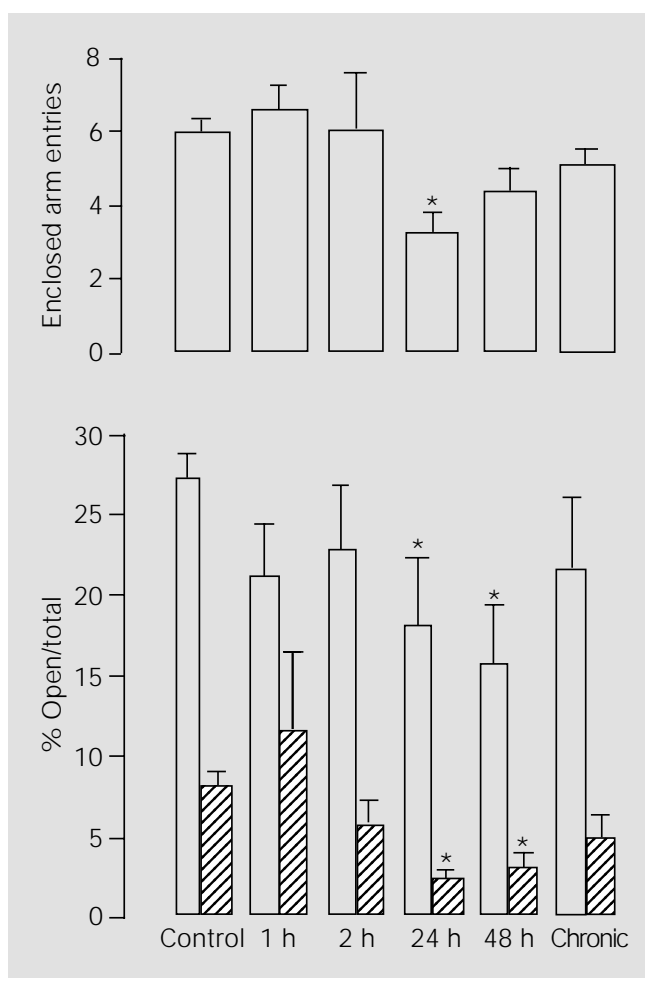

plus-maze was elevated $50 \mathrm{~cm}$ above the floor. Experiments were carried out in a sound-attenuated, temperature-controlled room, illuminated by two $40-\mathrm{W}$ fluorescent lights placed $1.3 \mathrm{~m}$ away from the elevated plus-maze. The observer stayed in the same room, $1 \mathrm{~m}$ or so away from the maze.

The groups consisted of animals tested 1 , 2, 24 or $48 \mathrm{~h}$ after the 2-h period of acute immobilization. An additional group was restrained daily for $2 \mathrm{~h}$ for 7 days, and tested in the plus-maze $24 \mathrm{~h}$ after the last restraint period. The restraint period was chosen based on previous findings from this and other laboratories showing that it is effective to change exploratory activity in the elevated plus-maze and/or an open arena $(2-5,9,10)$. The number of entries with the four paws, and time spent in the open or enclosed arms of the elevated plus-maze were recorded for 5 min. Control animals $(\mathrm{N}=65)$ remained in their home cages throughout the experiment.

The percent of open arm entries ( $100 \mathrm{x}$ open/total entries) and of time spent in the open arms (100 open/open + enclosed) was calculated for each rat. These data and the number of enclosed and open arm entries were analyzed by one-way ANOVA followed by the Duncan test for multiple comparisons. Since a significant effect on the number of enclosed arm entries was observed, analysis of covariance (ANCOVA) using this variable as covariate was also applied to the percentage of entries and time spent in open arms (11).

The results are shown in Figure 1. Restrained rats showed a decreased number of entries $\left(\mathrm{F}_{5,134}=4.84, \mathrm{P}<0.01\right.$; Duncan test, $\mathrm{P}<0.05)$, percentage of entries $\left(\mathrm{F}_{5,134}=2.7\right.$, $\mathrm{P}<0.05$; Duncan test, $\mathrm{P}<0.05$ ) and percentage of time spent $\left(\mathrm{F}_{5,134}=3.9, \mathrm{P}<0.01\right.$; Duncan test, $\mathrm{P}<0.05$ ) in the open arms, as compared to non-immobilized animals, 24 and $48 \mathrm{~h}$ after stress. The former group also showed a decreased number of entries into enclosed arms $\left(\mathrm{F}_{5,134}=5.4, \mathrm{P}<0.01\right.$; Duncan test, $\mathrm{P}<0.05)$. No effect was found in ani- 
mals tested in the plus-maze 1 or $2 \mathrm{~h}$ after restraint stress. ANCOVA using the number of entries into enclosed arms as the covariate showed that, although there was a trend in the number of entries into open arms $\left(\mathrm{F}_{5,133}=\right.$ $2.22, \mathrm{P}=0.056)$, no significant effect was found on this variable or on the percentage of time spent in the open arms. Repeated daily immobilization periods for one week induced tolerance to the restraint-induced decreased activity (Duncan test, $\mathrm{P}>0.10$ ).

The elevated plus-maze is a widely used animal model of anxiety (11). In this test, the percentage of open arm entries and time spent in the open arms has been validated as a measure of anxiety (11).

The maze used in the present experiment was modified by the addition of a small edge to the open arms. Although this procedure has been shown to reduce the anxiolytic effects of benzodiazepines in a different rat strain (12), we have been able to detect both anxiolytic and anxiogenic effects of different treatments, including benzodiazepine agonists and inverse agonists (13). This modification may have been responsible for a reduction in the percentage of time spent in the open arms in our laboratory as compared to others. The results for the nonstressed group in the present study, however, were not significantly different from those reported in several similar studies performed in our laboratory $(3,4,6)$.

Exposure to $2 \mathrm{~h}$ of restraint stress modified the rat behavior in the elevated plusmaze $24 \mathrm{~h}$ later, decreasing the exploration of open arms. A similar effect was found when the animals were tested $48 \mathrm{~h}$, but not when they were tested 1 or $2 \mathrm{~h}$ after stress. However, the restraint procedure also decreased the number of enclosed arm entries. Based on experimental evidence, this parameter has been proposed to reflect general exploratory activity (11). Considering that the significant effects on the number of entries and percentage of time spent in the open arms disappeared when the data were sub- mitted to ANCOVA using the number of enclosed arm entries as a covariate, the results indicate that the restraint stress resulted in a decrease in general activity.

A decrease in general exploratory activity in an open arena after restraint stress has been previously described (9). In the elevated plus-maze most studies found a decrease in the percentage of open arm entries and/or time spent in them $(2-5,10)$. However, results concerning the number of enclosed arm entries are conflicting, with reports of no change $(2,4,5)$ or decreased $(3,10)$ activity. One explanation for these conflicting results could be that an anxiogenic effect of restraint enhanced the aversive novelty aspect of the maze, inducing secondary changes in general activity. Similar reductions in general activity have been found after anxiogenic drugs or procedures such as FG-7142 (14) or ethanol withdrawal (15). Exposure to a previous aversive experience could conceivably increase anxiety when the animal is confronted by a new threatening situation represented by the novelty aspects of the elevated plus-maze. To test this possibility it would be interesting to repeat in previously stressed rats the factorial analysis study performed by File (11) in nonstressed animals.

Other groups have also found interference of previous stressful situations in animal models of anxiety $24 \mathrm{~h}$ later. For example, 15 min of restraint or forced swimming were able to decrease open arm exploration of the elevated plus-maze (16), whereas 30 min of immobilization increased defensive postures in a social test (17).

The lack of behavioral changes when the rats were tested 1 or $2 \mathrm{~h}$ after immobilization shows that a certain time is needed for the appearance of behavioral consequences of restraint stress in the elevated plus-maze performance. The mechanisms underlying this phenomenon are unknown. However, plastic changes in the central nervous system are probably needed for its development. It 
has already been shown that restraint and other forms of stress induce expression of immediate early genes such as $c$-fos or $c$-jun in several brain regions, including the hippocampus (18-20). These genes are proposed to act as "third messengers", leading to alteration of target genes expression related to some stress-induced long-lasting changes in animal and human behavior (1). We have also recently shown that cycloheximide, a protein synthesis inhibitor, after either $i c v$ or hippocampal administration, attenuates the behavioral consequences of restraint stress $(4,5)$.

The behavioral changes induced by restraint stress on plus-maze performance disappeared when the animals were submitted to repeated 2-h daily immobilization periods. A similar effect was found by Kennett et al. (9), using an open arena instead of the elevated plus-maze. Both data suggest that animals become tolerant to repeated restraint stress. Interestingly, in Kennett's model tol- erant animals were more prone to showing signs of the "serotonergic syndrome" after systemic administration of a serotonin agonist, suggesting that stress tolerance was accompanied by signs of serotonin supersensitivity. This may involve the hippocampus since our group has shown that administration of 5HT1A agonists into this region attenuates the restraint-induced deficit of plusmaze open arm exploration $(2,3)$.

In conclusion, our results showed that a restraint stress experience induces behavioral changes in rats, expressed as a deficit in open and enclosed arm exploration of an elevated plus-maze 24 or $48 \mathrm{~h}$ later. They also suggest that daily repeated restraint induces tolerance to this effect.

\section{Acknowledgments}

The authors acknowledge the helpful technical support provided by J.C. de Aguiar.

\section{References}

1. Post RM (1992). Transduction of psychosocial stress into the neurobiology of recurrent affective disorder. American J ournal of Psychiatry, 149: 999-1010.

2. Guimarães FS, Del Bel EA, Padovan CM, Mendonça Netto $S \&$ Titze-de-Almeida $R$ (1993). Hippocampal 5-HT receptors and consolidation of stressful memories. Behavioural Brain Research, 58: 133-139.

3. Mendonça Netto SE \& Guimarães FS (1996). Role of hippocampal 5-HT1A receptors on elevated plus-maze exploration after a single restraint experience. Behavioural Brain Research, 77: 215-218.

4. Mendonça FH \& Guimarães FS (1998). Intra-hippocampal administration of cycloheximide attenuates the restraint-induced exploratory deficit of an elevated plus maze. Behavioural Brain Research, 91: 207-211.

5. Mendonça FH, Félix FH, Del Bel EA \& Guimarães FS (1996). Intraventricular cycloheximide attenuates the restraint-induced long-lasting effect on plus maze exploration. Brazilian J ournal of Medical and Biological Research, 29: 501-505.
6. Farabollini F, Fluck E, Albonetti ME \& File SE (1996). Sex differences in benzodiazepine binding in the frontal cortex and amygdala of the rat 24 hours after restraint stress. Neuroscience Letters, 218: 177-180.

7. Clement HW, Kirsch M, Hasse C, Opper C, Gemsa D \& Wesemann W (1998). Effect of repeated immobilization on serotonin metabolism in different rat brain areas and on serum corticosterone. J ournal of Neural Transmission, 105: 1155-1170.

8. Albonetti ME \& Farabollini F (1992). Behavioral responses to single and repeated restraint in male and female rats. Behavioural Processes, 28: 97-110.

9. Kennett GA, Dourish CT \& Curzon G (1987). Antidepressant-like action of 5HT1A agonists and conventional antidepressants in an animal model of depression. European J ournal of Pharmacology, 134: 265-274.

10. McBlane JW \& Handley SL (1994). Effects of two stressors on behaviour in the elevated X-maze: preliminary investigation of their interaction with 8-OH-DPAT. Psy- chopharmacology, 116: 173-182.

11. File SE (1992). Behavioural detection of anxiolytic action. In: Elliot J M, Heal DJ \& Marsden CA (Editors), Experimental Approaches to Anxiety and Depression. J ohn Wiley \& Sons, New York, 25-44.

12. Fernandes C \& File SE (1996). The influence of open arm ledges and maze experience in the elevated plus-maze. Pharmacology, Biochemistry and Behavior, 54: 31-40.

13. Russo AS, Guimarães FS, de Aguiar J C \& Graeff FG (1993). Role of benzodiazepine receptors located in the dorsal periaqueductal grey of rats in anxiety. Psychopharmacology, 110: 198-202.

14. Cole BJ, Hillmann M, Seidelmann D, Klewer M \& J ones GH (1995). Effects of benzodiazepine receptor partial inverse agonists in the elevated plus maze test of anxiety in the rat. Psychopharmacology, 121: 118-126.

15. Baldwin HA, Rassnick S, Rivier J, Koob GF \& Britton KT (1991). CRF antagonist reverses the "anxiogenic" response to ethanol withdrawal in the rat. Psychophar- 
macology, 103: 227-232.

16. Martijena ID, Calvo N, Volosin M \& Molina VA (1997). Prior exposure to a brief restraint session facilitates the occurrence of fear in response to a conflict situation: behavioral and neurochemical correlates. Brain Research, 752: 136-142.

17. Albonetti ME \& Farabollini $F$ (1995). Effects of single restraint on the defensive behavior of male and female rats. Physiol- ogy and Behavior, 57: 431-437.

18. Lino de Oliveira C, Guimarães FS \& Del Bel EA (1997). c-jun mRNA expression in the hippocampal formation induced by restraint stress. Brain Research, 753: 202208.

19. Sharp FR, Sagar SM, Hicks K, Lowenstein D \& Hisanaga K (1991). c-fos mRNA, Fos, and Fos-related antigen induction by hypertonic saline and stress. J ournal of Neu- roscience, 11: 2321-2331.

20. Titze-de-Almeida R, Lino de Oliveira $C$, Shida HW, Guimarães FS \& Del Bel EA (1994). Midazolam and the N-methyl-Daspartate (NMDA) receptor antagonist 2amino-7-phosphono-heptanoic acid (AP-7) attenuate stress-induced expression of cfos mRNA in the dentate gyrus. Cellular and Molecular Neurobiology, 14: 373-380. 